\title{
ANALYSIS OF THE DIFFERENCES IN ENERGY SIMULATION RESULTS BETWEEN BUILDING INFORMATION MODELING (BIM)-BASED SIMULATION METHOD AND THE DETAILED SIMULATION METHOD
}

\author{
Seongchan Kim \\ Western Illinois University \\ 1 University Circle \\ Macomb, IL 61455, USA
}

\author{
Jeong-Han Woo \\ Milwaukee School of Engineering \\ 1025 N. Broadway \\ Milwaukee, WI 53202, USA
}

\begin{abstract}
Building Information Modeling (BIM)-based simulation models have been used to automate lengthy building energy modeling processes and it enable fast acquisition of results. Recent improvements of simulation programs have continued to the increase in the use of energy simulation in sustainability studies at the earlier design stage. However, it is often difficult to leverage the full potential of BIM due to inadequate information exchange between BIM models and simulation programs. Ambiguous assumptions on many simulation parameter values could result in a significant chance of misunderstanding on the predicted energy performance. The main objective of this study is to identify the differences in energy simulation results between detailed simulation method (DOE 2.2 simulation engine) and BIM-based simulation method.
\end{abstract}

\section{INTRODUCTION}

\subsection{Building Information Modeling (BIM)}

Building Information Modeling (BIM) enables the Architecture, Engineering, and Construction (AEC) industry to achieve interoperability and data integration among the different components of building systems. It integrates the description of a building such as 3D geometries, materials, building structures, Mechanical, Electrical, and Plumbing (MEP) systems, occupants, etc. into an intelligent format that could be used to study building energy performance. BIM models can be extended to store energy performance data such as power consumption, temperature, $\mathrm{CO}_{2}$ emissions, occupancy and humidity. Furthermore, the adoption of the sustainable guidelines such as LEED ${ }^{\mathrm{TM}}$ by federal, state and local governments calls for more comprehensive BIM models describing environmental performance such as indoor air quality, water consumption, and solid and hazardous waste (USGBC 2009).

However, current BIM processes and technologies leave much to be improved in terms of interoperability. A major limitation of the BIM interoperability research conducted to date is that little of it has examined the extendibility of BIM for building energy simulation. Current data exchange protocols support partial interoperability in exchanging data among BIM software tools. Although the issues of standards and interoperability have been addressed, most simulation programs still use very limited BIM data for simulation.

\subsection{Data Exchange and Interoperability}

Building energy simulation models have been used to identify the most cost-effective energy system and evaluate the energy performance of a building. the quality and accuracy of energy performance simulation 


\section{Kim and Woo}

depends critically on building data used in the simulation process. Accurate energy simulation models should represent actual operating conditions and real energy performance of the buildings. However, the simulation results are often comprised by uncertainty, improper statistics, and vague assumption regarding actual conditions of the buildings. Most of the simulation programs allow the users to insert default values derived from vague assumptions on unavailable simulation parameters. These insufficient data and many assumptions for simulation can result in a significant chance of misunderstanding and inaccuracy in simulation results. The variation between predicted and actual energy performance in the same building is estimated to be greater than 30 percent (Soebarto and Williamson 2001; Yudelson 2010). Previous studies such as HVAC BESTTEST (Neymark and Judkoff 2002) also show that there are significant differences in the simulation results of the same building that generated from different simulation programs.

With the proliferation of BIM technologies, BIM-based simulation models have been used to integrate building design and energy performance analysis in the early design phase. Furthermore, energy performance analysis can be improved significantly using a BIM-based energy simulation models that integrates detailed HVAC data directly extracted from BIM. As more information is accumulated in BIM, a higher level of design and construction expertise can be contributed, as required, for conducting various aspects of building energy performance. Furthermore, BIM-based energy models can be used to exchange energy-relevant information with various energy simulation programs to optimize energy performance analysis.

However, it is often difficult to leverage the full potential of BIM due to inadequate data exchange between BIM and energy simulation programs. Although the potential of using BIM for energy simulation is well known, a systematic approach to share the necessary information is yet lacking (Young, Jones and Bernstein 2009). Data exchange between BIM and simulation programs is currently limited to the transfer of 3D geometries of the building projects. Building systems data related with HVAC and internal loads such as occupancy and lighting should be included in data exchange between BIM and energy simulation programs to avoid any repetitive data inputs.

There have been few studies to link BIM with building simulation programs via Industry Foundation Classes (IFC) or Green Building XML schema known as gbXML data formats. Lawrence Berkeley National Laboratory (LBNL) developed an IFC-HVAC interface between BIM and EnergyPlus. This software enables HVAC and schedule data to be exported directly and formatted to generate EnergyPlus input files (Bazjanac 2008). This study intended to improve interoperability and resolve inefficient data exchange on HVAC design data. The second option is to import building geometries into eQUEST via gbXML that is an exchange format originally created to exchange building geometry with DOE-2 or EnergyPlus (Malie 2007). Several simulation programs including IES VE, Trane Trace, and Autodesk Green Building Studio (GBS) support import/export via gbXML data format. Maile et al. (2007) used Autodesk GBS in order to convert gbXML files into DOE-2 or EnergyPlus input files. GBS does not provide the functionality to transfer detailed data of the HVAC system that would be needed for building energy simulation.

Woo et al. (2010) developed a middleware called MCRP Pro using XML parsing engine to integrate sensor data with BIM via an Open Database Connectivity (ODBC) protocol. MCPR pro is developed as a building baseline database management system via RDBLink which is provided in 2009 Revit application programming interface (API). RDBLink is capable of pushing a variety of property changes that are made in the DBMS back to their corresponding elements in Revit. Necessary parameters for energy simulation were added in Revit and accessed directly from the DBMS. A prototype system was developed using .NET programming languages, including Visual Basic and C\#. The parsing engine used pre-defined algorithms to parse the data and to send and receive data from different data protocols, normalize the data, and exchange it in an XML format. While the above studies developed methodologies to improve interoperability between BIM and energy simulation programs, very few studies conducted to evaluate the differences of simulation results produced from detailed simulation and BIM-based simulation. 


\subsection{Overview}

The main objective of this study is to identify the differences in energy simulation results between detailed simulation method (DOE 2.2 simulation engine) and BIM-based simulation method. In order to compare the detailed simulation method and BIM-based simulation method with DOE 2.2 simulation engine, the base-case simulation model was developed based on the average characteristics of commercial buildings being built to the specifications of the F.W. Dodge survey data. Then, the characteristics of fenestration, envelope properties, and HVAC equipment have been defined based on the ASHRAE Standard 90.1 -2007(ASHRAE 2007).

The minimum requirements of ASHRAE Standard 90.1 are based on the climate zone. For this analysis, an office building (122ft x 122ft, 6-stories in height) located in New York was used and the envelope and glazing characteristics are assigned for the building. TMY2 weather file for New York was used to carry out the simulations.

\subsection{Building Configurations}

Since ASHRAE Standard 90.1-2007 does not require a specific aspect ratio or orientation, the basic building shape (122 ft x $122 \mathrm{ft}$, 6-story) and 40\% window-to-wall area ratio (WWR) are used for the simulation because $40 \%$ is the maximum WWR of the proposed design on ASHRAE 90.1. Figure 1 shows a pictorial explanation of (a) the simulation input model development by eQUEST which uses DOE 2.2 simulation engine, and (b) BIM model developed by AutoDesk Revit Architecture and MEP, which will be converted to the simulation input files. Figure 1(a) shows only three floors because middle floors from second to fifth floor were modeled by the multiplier function because these floors have the same geometry and building components.

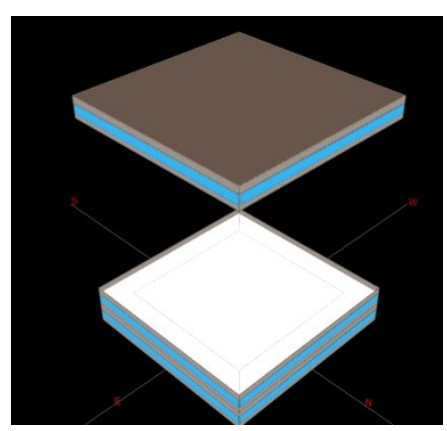

(a)

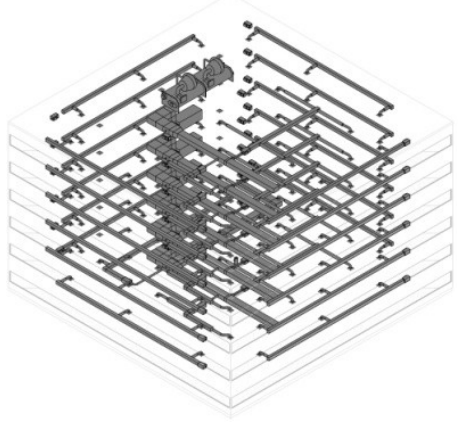

(b)

Figure 1: (a) Base case model developed by eQUEST, and (b) BIM based model by AutoDesk Revit Architecture and MEP.

\subsection{Building Envelope}

Exterior walls were modeled as 2"x4" steel-framed with studs 16" O.C. and insulation between the studs. Roofs were modeled as having continuous insulation above deck. Slab-on-grade floors were modeled for the first floor, and steel-joist floors were used between the floors. Overall U-values of wall and roof for the base case building were lower than the assembly maximum from ASHRAE standard 90.1, which means that the thermal properties of wall and roof are better than minimum requirements. 


\section{Kim and Woo}

Table 1 shows the building characteristics of fenestration and envelope properties for Zone 4A from ASHRAE Standard 90.1

Table 1: Building characteristics of fenestration and envelope properties of ASHRAE Standard 90.1

\begin{tabular}{|c|c|c|c|c|}
\hline \multicolumn{2}{|c|}{ Fenestration properties $(30.1-40.0 \% \mathrm{WWR})$} & \multicolumn{3}{|c|}{ Envelope properties } \\
\hline U-factor & SHGC & Wall U-valu & & Roof U-value \\
\hline \multirow{2}{*}{0.57} & \multirow{2}{*}{.39} & Assembly Maximum & 0.124 & .065 \\
\hline & & Insulation Min. R-value & 13 & 19 \\
\hline
\end{tabular}

\subsection{Building System}

Based on ASHRAE 90.1, non-residential buildings that are higher than four floors or larger than 25,000 square feet should be modeled with a multi-zone variable air volume system with zone reheat. The terminal units should be modeled with hot water reheat. If the building is greater than $150,000 \mathrm{ft}^{2}$, or is more than 5 stories, the baseline cooling source should be water-cooled chillers. Since the base case building is $89,304 \mathrm{ft}^{2}$ (122 ft x 122ft, 6-story), multi-zone variable air volume system with hot water reheat and water-cooled chillers were used for the HVAC system.

For chiller staging, ASHRAE 90.1 requires that when the peak cooling load met by the baseline chillers is between 300 and 600 tons, two or more equal sized water-cooled chillers should be modeled for the baseline case. For boiler staging, buildings ranging in size from 15,000 to $120,000 \mathrm{ft}^{2}$ of conditioned area should be modeled with two boilers. Since the chiller size from DOE-2.2 simulations of base case building is 570 tons $\left(6.835 \times 10^{6} \mathrm{Bth} / \mathrm{hr} / 12000=569.6\right.$ tons $)$ and building size is $89,304 \mathrm{ft}^{2}$ which is between 15,000 and $120,000 \mathrm{ft}^{2}$, two chillers and two boilers were used for the base case simulation model. In addition, separate thermal blocks were assumed for interior and perimeter spaces.

\subsection{Comparison of base case model and BIM based model}

In order to locate the difference between base case model and BIM based model, eQUEST user interface and text editor tool were used after converting BIM based model to DOE 2.2 input file through gbXML. The 15 measures were found to be significantly different and Table 2 shows the comparison of base case model and BIM based model.

In order to investigate the impact of above measures, the simulation scenarios were set up as Table 3. Each scenario is accumulative, so the simulation started from the original BIM based simulation model and modifications were performed on previous simulation input file based on simulation scenarios.

\section{SIMULATION RESULTS}

\subsection{Original BIM base simulation model}

After converting BIM model to DOE-2.2 simulation input through gbXML, the building shape was checked by eQUEST user interface. Simulation model is a 6-story building, $13 \mathrm{ft}$ height each floor, and consists of $9 \mathrm{ft}$ floor-to-ceiling and 4ft ceiling-to-next floor as a plenum. However, it was notified that after converting BIM model to simulation input, 4ft ceiling-to-next floor exterior surfaces were automatically converted to exterior shading surface (Figure 2). Since thermal properties for the windows, walls, roof, and underground floor were not entered when developing the BIM model using Revit Architecture and MEP, they were set by assumptions from conversion process of BIM. 


\section{Kim and Woo}

Table 2. Comparison between base case model and BIM based model

\begin{tabular}{|c|c|c|}
\hline Items & Base case & $\begin{array}{l}\text { BIM based simulation input } \\
\text { after conversion to DOE } 2.2 \\
\text { input }\end{array}$ \\
\hline Geometry & $\begin{array}{l}6 \text { story with plenum } \\
\text { Floor to ceiling: 9' } \\
\text { Plenum height: 4' }\end{array}$ & $\begin{array}{l}6 \text { story without plenum } \\
\text { (Plenum converted to exte- } \\
\text { rior shadings) } \\
\text { Floor to ceiling: 9' } \\
\text { Exterior shading height: 4' }\end{array}$ \\
\hline Wall U-value & 0.045 & 0.068 \\
\hline Roof U-value & 0.046 & 0.043 \\
\hline Underground Floor U-value & 0.010 & $\mathrm{~N} / \mathrm{A}$ \\
\hline Glazing U-value & 0.57 & 0.31 \\
\hline SHGC & 0.39 & 0.40 \\
\hline Lighting Power Density (LPD) & $1.0 \mathrm{~W} / \mathrm{ft}^{2}$ & $1.017 \mathrm{~W} / \mathrm{ft}^{2}$ \\
\hline Equipment Power Density (EPD) & $0.75 \mathrm{~W} / \mathrm{ft}^{2}$ & $1.352 \mathrm{~W} / \mathrm{ft}^{2}$ \\
\hline Number of people in space & $200 \mathrm{ft}^{2} /$ person & $100 \mathrm{ft}^{2} /$ person \\
\hline Heating temperature & $70.0^{\circ} \mathrm{F}$ & $72.0^{\circ} \mathrm{F}$ \\
\hline Cooling temperature & $75.0^{\circ} \mathrm{F}$ & $73.9^{\circ} \mathrm{F}$ \\
\hline Boiler efficiency & $75 \%$ & $83 \%$ \\
\hline Chiller Coefficient of Performance (COP) & 5.5 & 5.0 \\
\hline Domestic hot water Heat Input Ratio (HIR) & 1.25 & 1.74 \\
\hline Chiller staging \& Boiler staging & 2 & 1 \\
\hline
\end{tabular}

Table 3. Cumulative simulation scenarios

\begin{tabular}{|c|l|}
\hline Sim. No. & \multicolumn{1}{c|}{ Changes from original BIM based simulation model } \\
\hline 1 & Original BIM based simulation model \\
\hline 2 & Fixed geometry \\
\hline 3 & Modified Building envelope \\
\hline 4 & Changed LPD, EPD and schedules of LPD and EPD based on base case model \\
\hline 5 & Changed the number of people based on base case model \\
\hline 6 & Changed the heating and cooling temperature, and heating and cooling schedule \\
\hline 7 & Changed the number of boilers and efficiency \\
\hline 8 & Changed the number of chillers and COP \\
\hline 9 & Changed the DHW efficiency \\
\hline
\end{tabular}

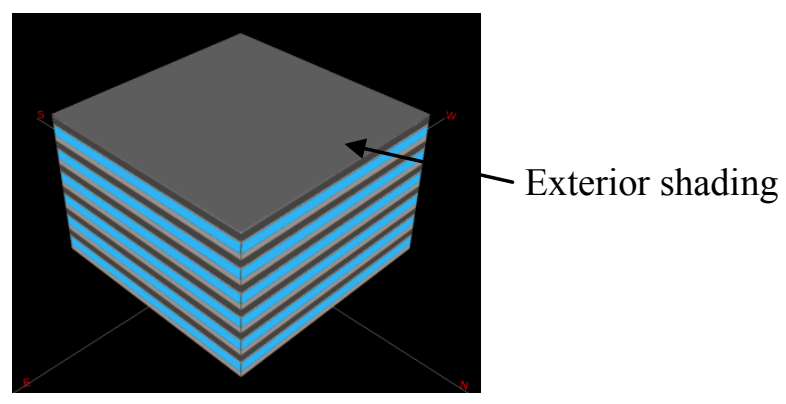

Figure 2: Original BIM based model after converting to DOE 2.2 simulation input. 
Using this original BIM based simulation model, the first simulation was performed and Figure 3 shows the simulation results of each category including lights, miscellaneous equipment, space heating, space cooling, heat reject, pump and aux, ventilation and domestic hot water per year. Since the original BIM based simulation model didn't match with base case model developed by eQUEST, each category shows the difference between two models and total energy calculation difference was $46.8 \%$ (4,072 MBTU/year vs. 5,978 MBTU/year).

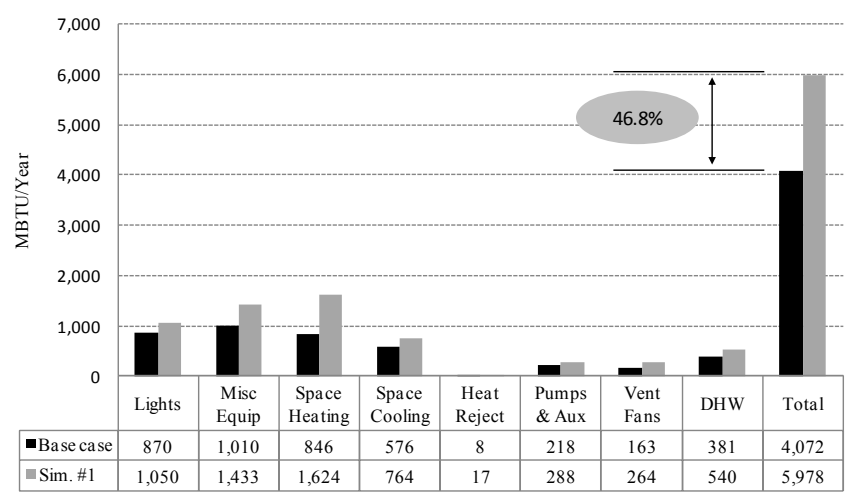

Figure 3: Energy consumption comparison: base case vs. original BIM based simulation model

\subsection{Changing the exterior shading surface to plenum surface.}

As mentioned, the original BIM based simulation model recognized the plenum as the exterior shading (Figure 2). Therefore, the second simulation was performed after correcting the exterior shading area to plenum space. Figure 4 shows the simulation results, which still shows $49.1 \%$ total energy difference (4,072 MBTU/year vs. 6,070 MBTU/year).

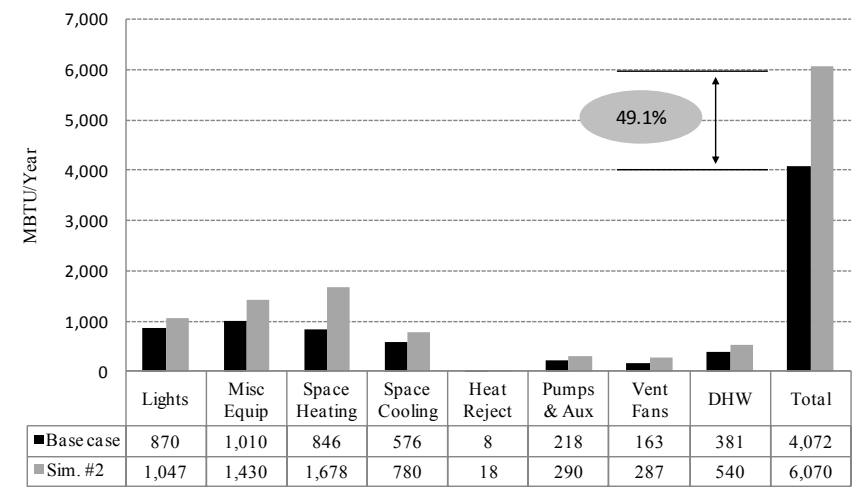

Figure 4: Energy consumption comparison: base case vs. BIM based model with fixed plenum surface

\subsection{Changing the building envelope thermal properties based on the base case simulation model.}

Since the base case model developed by eQUEST and BIM based simulation model had the different building envelope thermal properties such as U-value of wall, roof and floor, and U-value and SHGC of windows, modifications were performed on the BIM based simulation model which was used for the second simulation. The converted BIM based simulation model didn't have the underground floor and had the exterior roof materials between the floor instead of ceiling, so it was needed to add the underground floor and change the roof materials to ceiling materials. 
After matching the thermal properties of BIM model to base case simulation model, the third simulation was performed. The heating energy consumption increased from 1,678 MBTU/year to 2,468 MBTU/year and the cooling energy consumption increased from $780 \mathrm{MBTU} / \mathrm{year}$ to $791 \mathrm{MBTU} / \mathrm{year}$ from the second simulation. Total energy consumption difference between base case simulation model and BIM based model shows $69.8 \%$ (4,072 MBTU/year vs. 6,915 MBTU/year).

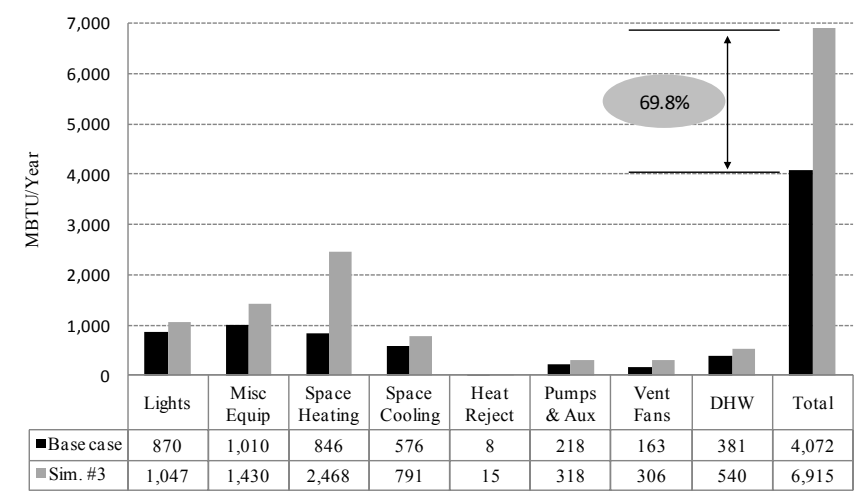

Figure 5: Energy consumption comparison: base case vs. BIM based model with fixed thermal properties

\subsection{Changing LPD, EDP and schedules of LPD and EPD based on base case model.}

Base case model used $1.0 \mathrm{~W} / \mathrm{ft}^{2}$ and $0.75 \mathrm{~W} / \mathrm{ft}^{2}$ as Lighting Power Density (LPD) and Equipment Power Density (EPD), respectively, and BIM based model used $1.017 \mathrm{~W} / \mathrm{ft}^{2}$ and $1.352 \mathrm{~W} / \mathrm{ft}^{2}$ as LPD and EPD, respectively. Figure 6 shows the lighting and equipment profile of the base case which is the default schedules of office from eQUEST. Figure 7 shows the lighting and equipment profile of BIM based model.

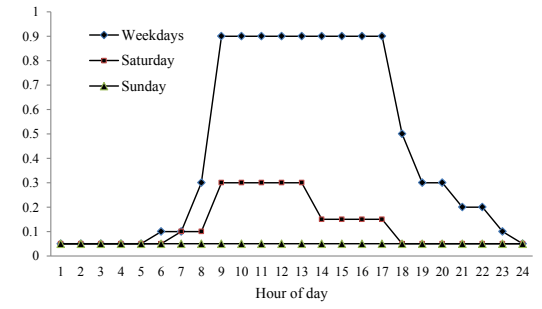

(a)

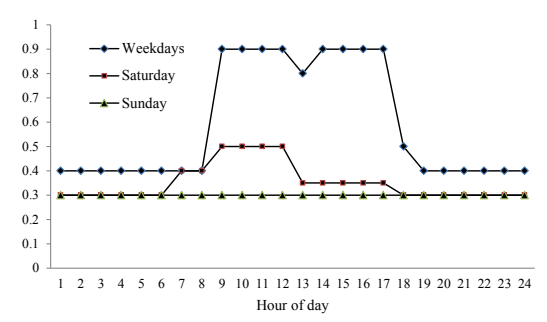

(b)

Figure 6: (a) Lighting profile of base case model, and (b) Equipment profile of base case model

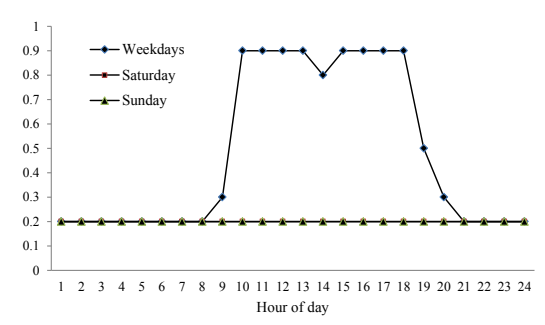

(a)

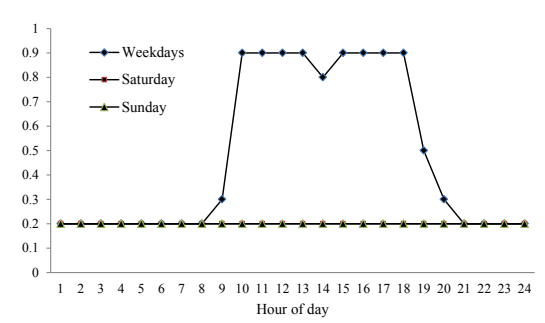

(b)

Figure 7: (a) Lighting profile of BIM based model, and (b) Equipment profile of BIM based model 
Since two models use different LPD, EPD and schedules, BIM based model was fixed to have the same LPD, EPD and schedules with base case model and the fourth simulation was performed. Simulation results from Figure 8 shows that this measure reduced: 1) total energy difference from $69.8 \%$ to $38.8 \% ; 2$ ) lights energy consumption from $1047 \mathrm{MBTU} /$ year to $849 \mathrm{MBTU} /$ year, which is a $2.5 \%$ difference $(20.4 \%$ at the simulation \#3) between base case and BIM based model; and 3) equipment energy consumption from 1,430 MBTU/year to $985 \mathrm{MBTU} /$ year, which is also a $2.5 \%$ difference (41.6\% at the simulation \#3) between the two simulations.

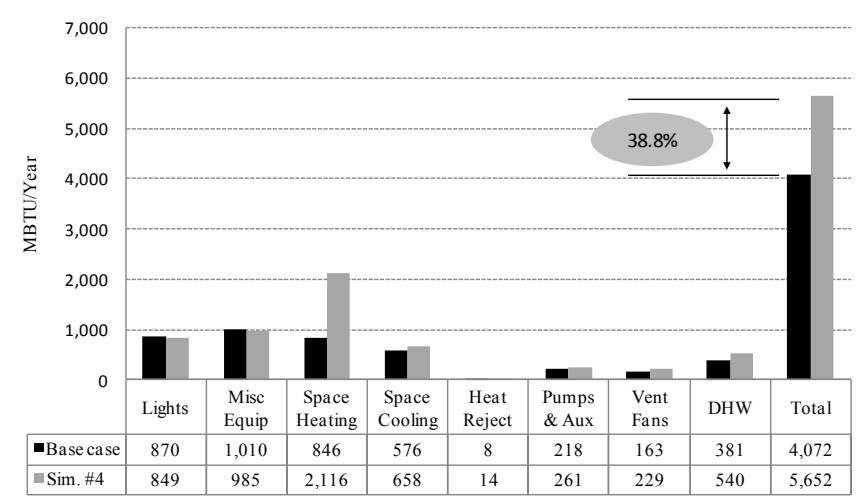

Figure 8: Energy consumption comparison: base case vs. BIM based model with fixed LPD and EPD

\subsection{Changing the number of people in the space.}

While comparing the base case and BIM base input file, it was found that two models used different people density in the space $\left(200 \mathrm{ft}^{2} /\right.$ person for base case and $100 \mathrm{ft}^{2} /$ person for BIM based model). Since number of people affects the internal heat load and outdoor air quantity for the system calculation, it could result in different simulation results. In order to investigate the impact of this measure, the number of people was changed as the base case model. Simulation results in Figure 9 shows that: 1) there were little change in space heating (from 2,116 MBTU/year to 2,081 MBTU/year), cooling (from 658 MBTU/year to $668 \mathrm{MBTU} /$ year), pumps (from $261 \mathrm{MBTU} /$ year to $264 \mathrm{MBTU} / \mathrm{year}$ ) and vent fans (from $229 \mathrm{MBTU} /$ year to $233 \mathrm{MBTU} /$ year); and 2) total energy difference decreased to $38.4 \%$ from $38.8 \%$.

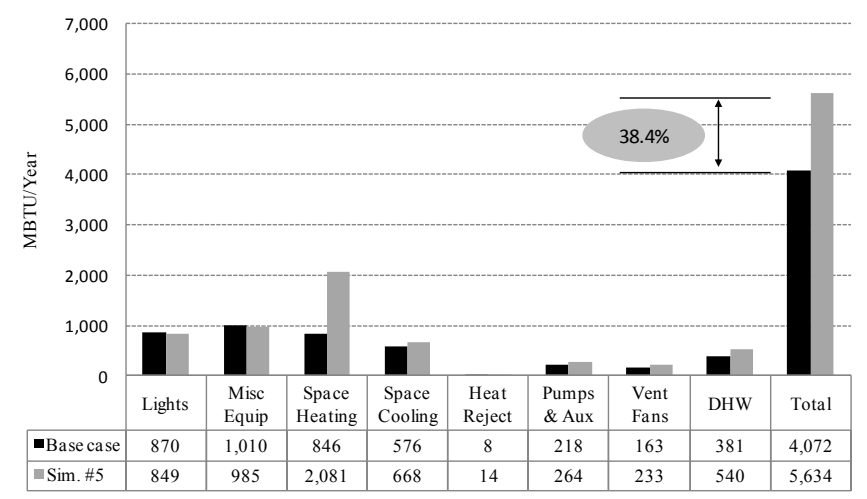

Figure 9: Energy consumption comparison: base case vs. BIM based model with fixed number of people. 


\section{Kim and Woo}

\subsection{Changing the heating and cooling temperature, and heating and cooling schedule.}

Heating and cooling temperature of base case model were $70^{\circ} \mathrm{F}$ and $75^{\circ} \mathrm{F}$, respectively based on ASHRAE 90.1, and those of BIM based model were $72^{\circ} \mathrm{F}$ and $73.9^{\circ} \mathrm{F}$, respectively. Two simulation models also had different heating and cooling schedules. Figure 10 shows the heating and cooling schedule of base case model and Figure 11 shows the heating and cooling schedule of BIM based model.

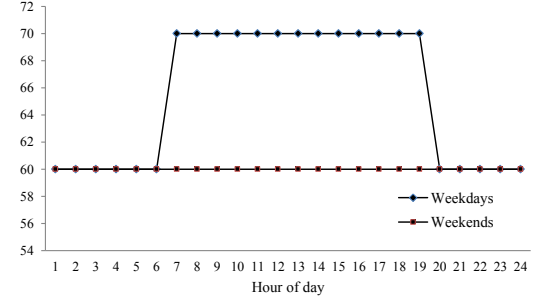

(a)

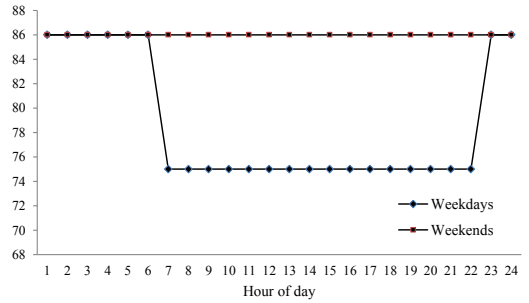

(b)

Figure 10: (a) Heating schedule, and (b) Cooling schedule of base case model

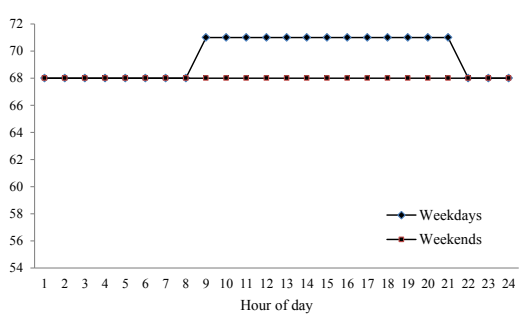

(a)

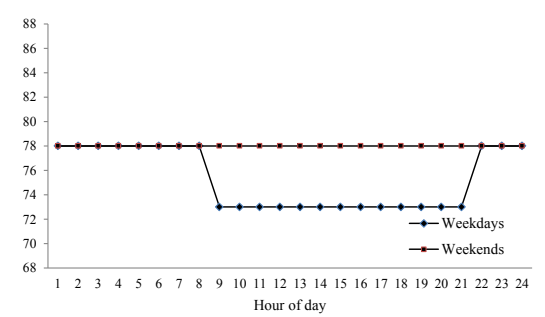

(b)

Figure 11: (a) Heating schedule, and (b) Cooling schedule of BIM based model

After the simulation, it was found that heating and cooling temperature and schedules played a major role in matching energy simulation results of two models. Results in Figure 12 shows that this measure decreased: 1) total energy difference to $2.0 \%$ from $38.4 \%$; 2) space heating from $2,081 \mathrm{MBTU} /$ year to 826 MBTU/year, which is a $2.4 \%$ difference $(146.0 \%$ at the simulation \#5) between base case and BIM based model; and 3) space cooling from $668 \mathrm{MBTU} /$ year to $539 \mathrm{MBTU} /$ year, which is a $6.4 \%$ difference (15.9 \% at the simulation \#5) between base case and BIM based model. It was also found that it required the authors to check the geometry of the model before system simulation. Since the original model didn't have the plenum space, simulation model without plenum space could result in significant different simulation results.

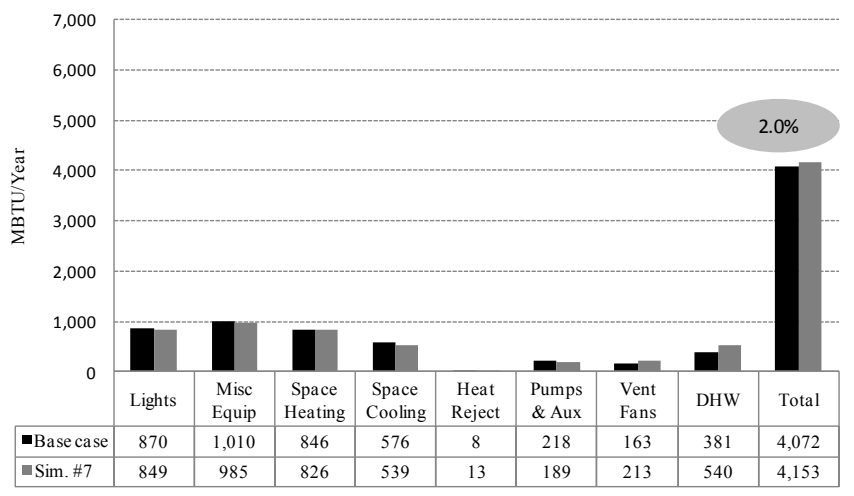

Figure 12: Energy consumption comparison: base case vs. BIM based model with fixed heating and cooling temperature and schedule. 


\section{Kim and Woo}

\subsection{Changing the number of boilers and efficiency.}

For the base case model, the code requires two hot water gas boilers and a minimum boiler thermal efficiency of $75 \%$, while BIM based simulation model had one gas boiler with $83 \%$ boiler thermal efficiency. In order to investigate the impact of energy consumption of this measure, BIM based model was modified to have two boilers with $75 \%$ thermal efficiency. Figure 13 shows the simulation results. This measure: 1 ) reduced total energy difference from $2.0 \%$ to $1.9 \%$; and 2) increased space heating from $826 \mathrm{MBTU} / \mathrm{year}$ to $831 \mathrm{MBTU} /$ year, which is a $1.7 \%$ difference $(2.4 \%$ at the simulation \#6) between base case and BIM based model.

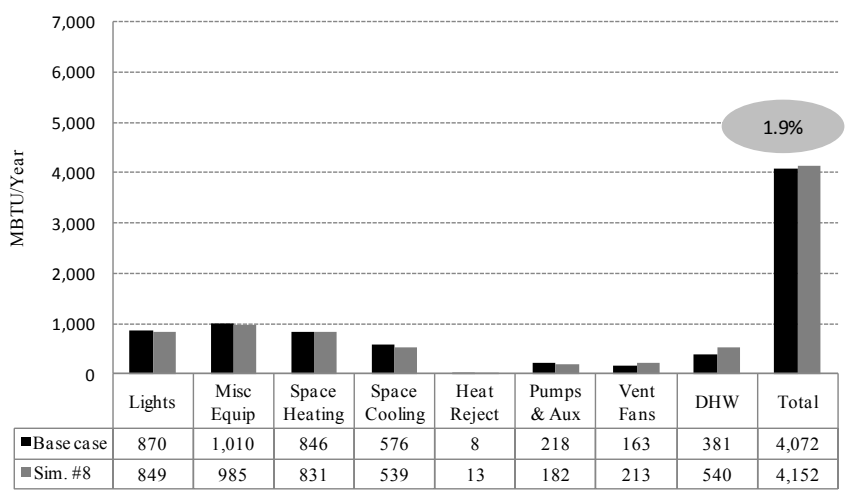

Figure 13: Energy consumption comparison: base case vs. BIM based model with fixed numbers of boiler and efficiency.

\subsection{Changing the number of chillers and COP.}

Base case model had two centrifugal chillers installed with a COP of 5.5, which is the minimum code requirement and BIM based model had one centrifugal chiller with a COP of 5.0. The number of chiller and COP for BIM based model were changed based on base case model with new chiller performance curve. Figure 14 shows the simulation results. This measure: 1) reduced total energy difference from $1.9 \%$ to 1.7 $\%$; 2) decreased space cooling from $539 \mathrm{MBTU} /$ year to $516 \mathrm{MBTU} / \mathrm{year}$, which is a $10.5 \%$ difference (6.4 \% at the simulation \#7) between base case and BIM based model; 3) decreased heat reject energy from $13 \mathrm{MBTU} /$ year to $9 \mathrm{MBTU} / \mathrm{year}$, which is a $4.9 \%$ difference (5.6\% at the simulation \#7) between base case and BIM based model; and 4) increased pumps' energy from $182 \mathrm{MBTU} /$ year to 197 MBTU/year, which is a $9.7 \%$ difference (16.7\% at the simulation \#7).

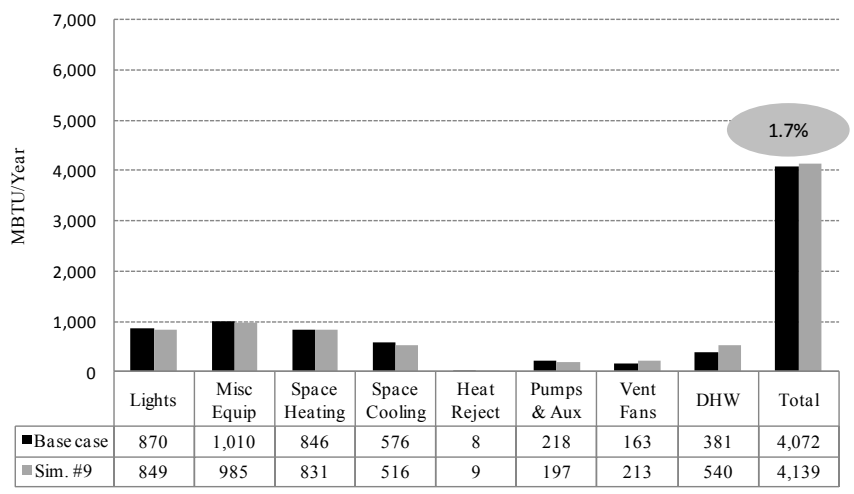

Figure 14: Energy consumption comparison: base case vs. BIM based model with fixed numbers of chiller and efficiency. 


\subsection{Changing the DHW efficiency.}

The code's minimum requirement for thermal efficiency for the service water system is $80 \%$, but thermal efficiency of the service water system of BIM based simulation model is much lower (58\%). This was changed to $80 \%$ to be identical with base case model. Figure 15 shows the simulation results. This measure: 1) increased total energy difference from $1.7 \%$ to $2.2 \%$; and 2) decreased domestic hot water from $540 \mathrm{MBTU} /$ year to $380.6 \mathrm{MBTU} /$ year with improvement of the efficiency of the service water system.

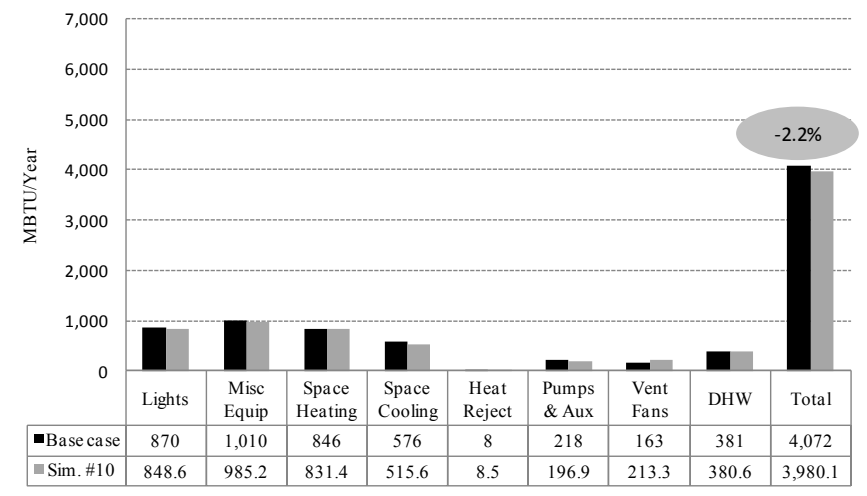

Figure 15: Energy consumption comparison: base case vs. BIM based model with fixed DHW efficiency.

\section{SUMMARY}

This paper examined, in detail, the difference between detailed simulation method and BIM based simulation method by identifying different measures which could affect the simulation results for a 6-story building in New York based on ASHRAE Standard 90.1-2004.

It was found that even though BIM-based simulation models have been used in order to simplify building energy modeling processes and achieve the results faster, the simulation results showed a large difference between the two models due to missing information on gbXML and many assumption on BIM based simulation model.

From the comparison between base case simulation and BIM based simulation results, it was found that the properties of HVAC system played a major role in accurate simulation results. Therefore, it requires that more specific information of HVAC system should be delivered from BIM model to simulation input through gbXML to reduce the numbers of assumptions.

It was also notified that the plenum space was recognized as exterior shading after converting BIM to simulation input. Therefore, it needs a verification process of converted geometry because there were possibilities of significant difference on geometry of the model with the converting process.

\section{REFERENCES}

ASHRAE (American Society of Heating, Refrigerating, and Air-conditioning Engineers). 2007. Standard 90.1-2007 - Energy Efficient Design of New Buildings Except Low-Rise Residential Buildings. Atlanta, GA: American Society of Heating, Ventilation and Air-conditioning Engineer.

Bazjanac, V. 2008. "IFC BIM-based Methodology for Semi-automated Building Energy Performance Simulation." In Proceedings of CIB W78, Proc. 25th conf., Improving the management of construction projects through IT adoption, Santiago, CL: 292-299. Universidad de Talca. ISBN 978-956-319361-9.

Maile, T., M. Fischer and V. Bazjanac. 2007. Building Energy Performance Simulation Tools - a LifeCycle and Interoperable Perspective, CIFE Working Paper \#WP107. Stanford University. 
Neymark, J. and R. Judkoff. 2002. International Energy Agency Building Energy Simulation Test and Diagnostic Method for Heating, Ventilating, and Air-Conditioning Equipment Models (HVAC BESTEST), A Report of IEA SHC Task 22, National Renewable Energy Lab, Golden, CO.

Soebarto, V. I. and T.J. Williamson. 2001. "Multi-criteria Assessment of Building Performance: Theory and Implementation." Building and Environment, Elsevier, 36(6), 681-690.

U.S. Green Building Council. 2009. "Green Building Research." US Green Building Council. June 15, 2009. ttp://www.usgbc.org/DisplayPage.aspx?CMSPageID=1718 (accessed June 15, 2009).

Woo, J-H., C. Diggelman, B. Abushakra and G. Corliss. 2010. "Achieving Energy Efficiency with AsBuilt BIM." In Proceedings of Ecobuild America, Washington D.C.

Young, N., S. Jones and H. Bernstein. 2009. The Business Value of BIM. New York: McGraw Hill.

Yudelson, J. 2010. Greening Existing Buildings. New York: Green Source/McGraw-Hill.

\section{AUTHOR BIOGRAPHIES}

SEONGCHAN KIM received his Ph.D. in Architecture from Texas A\&M University in August of 2006. Dr. Kim has been a faculty member at the Department of Engineering Technology at Western Illinois University since August 2008. His primary research areas of interest include sustainable construction, building energy simulation, building energy code analysis, BIM (Building Information Modeling), energy optimization in building design, and construction process simulation. Before joining Western Illinois University, Dr. Kim held professorial positions at Texas A\&M University as a visiting assistant professor and research associate. He performed various funded projects by the Texas State Legislature. He has been involved in various research consultation and presentation. His email address is s-kim7@wiu.edu.

JEONG-HAN WOO received his Ph.D. in Architecture from Texas A\&M University in August of 2005. Dr. Woo has been an active researcher in the field of Architectural Engineering and Construction Management, especially in BIM, building energy efficiency, and construction information technologies. He presented his research findings numerously at Construction Research Congress, ISARC (International Symposium on Automation and Robotics in Construction), ACADIA (Association of Computer Aided Design in Architecture), ASC (Associated Schools of Construction), and ASEE (American Society of Engineering Education). He has been served as Assistant Professor at the Architectural Engineering and Building Construction Department of MSOE from 2007 to present. His teaching area includes designbuild studio, BIM, construction estimating, scheduling, project management, and construction methods. His email address iswoo@msoe.edu. 